\title{
La familia Maestre - Zapata: un modelo de burguesía murciana. De la edad de oro a los límites del crecimiento
} $(1879-1958)^{1}$

The family Maestre-Zapata: a model of bourgeoisie family in Murcia. From their golden age to the limits of their growth (1879-1958).

\author{
Pedro M. Egea Bruno \\ Universidad de Murcia
}

\section{RESUMEN}

La familia Maestre Zapata ocupó un lugar destacado entre la burguesía murciana. La analizamos desde el punto de vista de su proyección económica, atendiendo a los mecanismos de acumulación: desde la estrategia matrimonial a la consolidación y ampliación de los negocios recibidos por aquella vía, sin olvidar el control de los resortes políticos y la construcción de una red de influencias sociales. Su trayectoria es inseparable de los años que les tocó vivir, entre 1879 y 1958, que acotan los extremos temporales de su edad de oro y su decadencia, donde se dieron la mano variables económicas y cambios políticos.

PALABRAS CLAVE: familia, parentesco, burguesía, Murcia, ss. XIX-XX

\footnotetext{
${ }^{1}$ El presente artículo se integra y forma parte del proyecto de investigación: Entornos sociales de cambio. Nuevas solidaridades y ruptura de jerarquías (siglos XVI-XX). HAR2017-84226-C6-1-P. Ministerio de Ciencia e Innovación. Gobierno de España.
} 


\begin{abstract}
The family Maestre Zapata occupied a prominent place among the bourgeoisie of Murcia. We analyse their socioeconomic role from the point of view of their economic projection, paying special attention to the accumulation mechanisms: from marriage strategy to consolidation and expansion of businesses received via kinship relationships, not forgetting the control of political resources and the construction of a network of social influences. The socio-political trajectory of this family is inseparable from the years they lived through, between 1879 and 1958, a period of time which encompasses their golden age and their decline, and where economic variables and political changes undoubtedlygo hand in hand.
\end{abstract}

KEY WORDS: family, kinship, bourgeoisie, Murcia, nineteenth and twentieth centuries

\title{
INTRODUCCIÓN
}

El capitalismo familiar español ha venido mereciendo una atención creciente por parte de la historiografía. Son ya numerosos los estudios sobre conocidas sagas empresariales. Nuestro interés se centra en los Maestre Zapata, que dejaron su impronta entre 1879 y 1958. Tres miembros marcaron sus hitos en la economía, la política y las relaciones sociales: Miguel Zapata Sáez, el creador de un importante imperio económico, con base en la sierra minera de Cartagena; su yerno, José Maestre Pérez, que lo expandió, y su nieto, Tomás Maestre Zapata, que protagonizó su declive, cumpliendo la ley de las tres generaciones.

Más allá, nos proponemos examinar el papel de la familia burguesa como vehículo económico, social y cultural, atendiendo a sus mecanismos de acumulación y reproducción: desde la inversión económica a la estrategia matrimonial, pasando por el control de los resortes políticos y la constitución de una red de influencias sociales, sin olvidar sus modos de vida y su orden mental.

Su trayectoria es inseparable de los años que les tocó vivir, donde se dieron la mano cambios económicos y políticos. El análisis combina, por tanto, el criterio cronológico con el temático, una intersección obligada en las historias de vida. Se trata, por lo demás, de un estudio de los grupos privilegiados, utilizando los sinónimos de elite y oligarquía, partiendo de la referencia señera de Tuñón de Lara, sin entrar en el debate abierto por la prosopografía, aunque utilizando algunos de sus conceptos. 
Para la investigación propuesta hemos recurrido a padrones municipales, inscripciones mineras, libros de asociaciones, actas de la Diputación Provincial, expedientes de incautación, registros de la propiedad expropiable, declaraciones de renta, instrumentos judiciales, diligencias policiales, informes y cartas privadas. Fondos documentales custodiados en archivos locales, provinciales y nacionales. La consulta de la prensa -incluidos los diarios oficiales- se ha mostrado fundamental para revelar la trazabilidad de la familia. Bibliografía primaria y secundaria contextualizan y contrastan la visión propuesta.

\section{MIGUEL ZAPATA SÁEZ: LA CONSTRUCCIÓN DE UN IMPERIO}

El origen de la fortuna familiar se remonta a Miguel Zapata Sáez (1841-1918), nacido en un pequeño caserío de la localidad murciana de San Javier. Los Zapata venían dedicándose a la venta de corderos al por mayor, especialmente a los mataderos de Barcelona, plaza a la que abastecían a través del puerto de Cartagena (Gallego, 2008: 448). Los beneficios obtenidos se destinaron a la compra de haciendas, una de ellas en La Manga del Mar Menor, dedicada por entonces a pastos y brozas. A finales del siglo XIX ya aparecían en los censos de contribución como grandes propietarios agrarios ${ }^{2}$.

El recorrido de Miguel Zapata es un caso representativo de reinversión de ahorro agrario (Prego 2005: 18). En 1865 se trasladó al Algar, una aldea de Cartagena, donde debió interesarse por el desarrollo minero que se estaba produciendo en su entorno inmediato, la sierra de Cartagena-La Unión (Egea 2014: 175). En 1879 estaba instalado en Portmán, epicentro de la actividad. Conocido como el Tío Lobo, se convirtió en un personaje legendario, entre la realidad y el mito.

Creó un trust de integración vertical, que contemplaba desde la extracción y el acarreo de minerales a la metalurgia del plomo, con dos fábricas de fundición en Portmán: La Orcelitana y Purísima Concepción. Atendió a la comercialización de sus productos, especialmente en los mercados ingleses, contando con sus atracaderos y su propia flota naviera. Participó en la fabricación de explosivos y montó en La Unión una factoría de maquinaria pesada, calderería y motores para las minas: La Maquinista de Levante, una de los mejores de España, con más de 200 operarios, compitiendo con ventaja con la Maquinista Terrestre de Barcelona, a la que consiguió arrebatar contratas de relevancia nacional. ${ }^{3}$

2 Boletín Oficial de la Provincia de Murcia, 10 de marzo de 1897.

${ }^{3}$ La Paz de Murcia, 21 de abril de 1894; Gaceta Minera y Comercial (Cartagena), 3 de diciembre de 1895 y Las Provincias de Levante (Murcia), 27 de agosto de 1896. 
A la agresividad empresarial -acosando a sus competidores con deudas o alentando motines- sumó la capitalización de sus instalaciones, adoptando los últimos adelantos tecnológicos (Egea 1979-80: 3-27). Nunca separó el trabajo de la vida familiar, instalando sus oficinas en el propio domicilio o muy cerca de él. ${ }^{4}$ No descuidó las relaciones mercantiles, con conexiones internacionales, desplazándose con frecuencia y hasta edad avanzada a París, Londres y Newcastle. También a Orán y Argel. En aquella dinámica, su hijo Miguel fue nombrado agente consular de Gran Bretaña en Portmán y, tras su muerte, él mismo asumió el cargo. ${ }^{5}$

No se le escapó el control de los trabajadores. En 1894 encabezó una solicitud al Ayuntamiento de La Unión para que Portmán tuviese un puesto de la Guardia Civil: “...para reprimir en caso preciso las alteraciones del orden que puedan ocasionarse por falta de acuerdo entre obreros y patronos". ${ }^{6}$ Además de ser aceptada, consiguió la contrata de alquiler de la casa cuartel. ${ }^{7}$ Impuso duras condiciones laborales, bajos salarios, pagos en especie y empleo de mano de obra infantil (Vilar, Egea y Victoria 1987). Las denuncias se mantuvieron en el tiempo, como las suscritas en 1915 por Pablo Iglesias y en 1923 por Manuel Llaneza. ${ }^{8}$ Las restricciones alcanzaban a la seguridad de los minados, lo que se traducía en una elevada siniestralidad, sucediéndose los juicios por indemnización, discutiendo cada céntimo, exhibiendo su mezquindad. En 1900 la vida de un obrero se saldaba con 1.950 pesetas. $^{9}$

Invirtió en otras explotaciones mineras, como las de hierro de Cehegín (Murcia), y en múltiples actividades económicas: seguros, transporte urbano, gas, negocios inmobiliarios, obras públicas, salinas, pesquerías, abastos y empresas de ocio. Trenzó una amplia red de relaciones personales, políticas y económicas, especialmente a través del Banco de Cartagena, del que era accionista (Conesa 2019). Inaugurado el 1o de junio de 1900, su consejo de administración quedó presidido por el conde de Romanones, siendo su vicepresidente Justo Aznar, empresario y dirigente del Partido Liberal, con una de cuyas hijas casaría su nieto José. Su director general era Joaquín Payá, del Partido Liberal y hombre de

${ }^{4}$ Las Provincias de Levante (Murcia), 2 de septiembre de 1897.

${ }^{5}$ El Tiempo (Murcia), 10 de noviembre de 1912.

${ }^{6}$ El Diario de Murcia, 13 de enero de 1894.

${ }^{7}$ Boletín Oficial de la Provincia de Murcia, 13 y 14 de mayo de 1890 y 28 de octubre de 1894.

8 Diario de las Sesiones de las Cortes. Congreso de los Diputados, sesión del 24 de noviembre de 1915, p. 419 y La Época (Madrid), 15 de octubre de 1923.

${ }^{9}$ El Diario de Murcia, 15 de septiembre de 1900. 
confianza de Romanones. En la sucursal de Murcia figuraba José de Echeverría, marqués de Villalba de los Llanos, con una de cuyas hijas contraería matrimonio su hijo Miguel. Entre los letrados de la institución se encontraban dos prebostes del Partido Conservador: Ángel Moreno Martínez e Isidoro de la Cierva Peñafiel ${ }^{10}$. El Banco era un entramado societario, en el que participaba la familia: compañía de seguros La Estrella, Sindicato para el Desagüe de las Minas del Llano del Beal y Sociedad Eléctrica Ahlemeyer. Detrás, según los casos, Romanones o Juan de la Cierva.

$\mathrm{Al}$ margen de las empresas, dispuso de fincas rústicas en San Javier y urbanas en Cartagena (Cabo Palos y El Algar). ${ }^{11}$ Destacaban sus residencias en Portmán -la Casa Grande- y San Javier -del mismo nombre-, frecuentada en verano por la familia. ${ }^{12}$ En fin, una extensa parcela -la de San Miguel- en el cementerio de Nuestra Señora de los Remedios de Cartagena. ${ }^{13}$ Una inversión en la que no andaba lejos el deseo de diferenciación social ni la concepción patriarcal, manteniendo la agrupación familiar más allá de la muerte (Ariès 1983: 429-430 y 432).

La política fue otro de los arbitrios utilizados, con beneficios tangibles, traducidos en contratos municipales, como los del mercado y la cárcel de Portmán; concesión de embarcaderos y habilitación de la aduana de aquel puerto, por la que importaba maquinaria para sus minas y fábricas y artículos de alimentación para su negocio de abastos. ${ }^{14}$ Militó en el Partido Conservador, del que, de su jefatura en La Unión, pasó a convertirse en uno de sus próceres regionales. ${ }^{15} \mathrm{Su}$ enorme fortuna fue un valor contemplado. En septiembre de 1899 intervino en la compra del diario Las Provincias de Levante, que se editaba en la capital murciana, reconvertido en portavoz de las filas conservadoras bajo la orientación de Juan de la Cierva, dándose la mano economía y política (Crespo 2000: 179).

${ }^{10}$ Estatutos del Banco de Cartagena reformados por la junta general de accionistas en sesión ordinaria celebrada el día 29 de diciembre de 1907, Cartagena, Sociedad Levantina de Artes Gráficas, 1908.

${ }^{11}$ Boletín Oficial de la Provincia de Murcia, 5 de diciembre de 1906.

${ }^{12}$ El Diario de Murcia, 24 de julio de 1894.

${ }^{13}$ La Tierra (Cartagena), 14 de marzo de 1919.

${ }^{14}$ Boletín Oficial de la Provincia de Murcia, 23 de septiembre y 29 de octubre de 1884, 20 de diciembre de 1890 y 24 de octubre de 1891; El Diario de Murcia, 20 de febrero y 18 de junio de 1898 .

${ }^{15}$ Las Provincias de Levante (Murcia), 4 de abril de 1898. 
Su riqueza llegó a ser considerable, con más de 2.000 empleados y obreros. En 1901 sus negocios se valoraban en 11 millones de pesetas. ${ }^{16}$ Se agrupaban bajo la firma de Miguel Zapata e Hijos, una clara apuesta por la sucesión indivisa como medio de asegurar el patrimonio familiar. En 1913, a la muerte de su último hijo varón, se transformó en Mancomunidad Miguel Zapata e Hijos, que en 1916 superaba los 24 millones de pesetas, el activo industrial más importante de la Región de Murcia (López-Morell y Pérez de Perceval 2016: 66).

El ascenso social fue paralelo al éxito económico. Su promoción se midió por la resonancia de sus eventos familiares. Peticiones de mano, bodas y sepelios testimoniarán la progresión alcanzada, tasada por la asistencia a los mismos de las más altas representaciones de la política, de los círculos empresariales, de los centros sociales de la burguesía, del Ejército y la Iglesia.

Las acciones filantrópicas, formaban parte de los valores morales de aquella clase (McDonogh 1989: 170). Difundidas por la prensa, mejoraron la imagen de Zapata y le sirvieron de escaparate a sus logros económicos. Unas obras de beneficencia en la que participaba toda la familia, con donativos al Hospital de Caridad de Portmán, al Asilo de Huérfanos, al Liceo de Obreros de La Unión y a la Casa de Expósitos de Cartagena. El mismo sentido puede atribuirse a su colaboración en celebraciones religiosas, como la semana santa de Cartagena, y actos patrióticos relacionados con las guerras de Marruecos y de Cuba. ${ }^{17}$

Mantuvo una estrecha relación con la Iglesia. A partir de 1893, en las visitas pastorales a Portmán, el obispo se hospedará en su casa, actuando de padrino junto con su mujer- en las ceremonias de confirmación, convertidas en acontecimientos populares ${ }^{18}$. Como albacea testamentario nombró a Antonio Álvarez Caparrós, párroco de La Unión, canónigo doctoral de la Santa Iglesia catedral de Cartagena y provisor del Obispado, presente en todos los actos religiosos de la familia -desde bodas y bautizos a los entierros-, al que unía una gran amistad, mantenida luego por sus herederos.

Apostó por la educación de sus hijos como valor social. Estudiaron en los colegios privados donde se formaban las elites españolas: los Sagrados Corazones de Jesús y María y la Compañía de Jesús (McDonogh 1989: 161-165). El varón, respondiendo a la mentalidad de la época, cursó el Bachillerato de Arte en el

${ }^{16}$ El Diario de Murcia, 6 de junio de 1901.

17 El Eco de Cartagena, 20 de noviembre de 1893 y Las Provincias de Levante (Murcia), 16 de noviembre de 1896.

${ }^{18}$ El Diario de Murcia, 22 de septiembre de 1893. 
Instituto de Segunda Enseñanza de la capital murciana y completó sus estudios suponemos que técnicos- en Argelia. No se podía ocultar que llevaba una vida más distendida, tentado por los yates y los coches de lujo.

A pesar de que solo tres de sus siete hijos llegaron a la edad adulta y de que sus dos hijas casaron con José Maestre Pérez, pudo tejer una red de contactos, donde mediaron la amistad política, las conexiones económicas y los vínculos sociales, todo aquello que contribuía a la buena marcha de los negocios.

La boda de su hijo Miguel, el 24 de enero de 1910, con Concha Echeverría, marquesa de Villalba de los Llanos, marcó el momento cenital de su proyección social. Era la aspiración de aquella burguesía de nuevo cuño, a la que Unamuno tildó de condes metalúrgicos. No fue un caso aislado. En 1915 Adolfo Wandosell -uno de los vástagos de otro minero de fortuna- se casó con María de las Mercedes de Echeverría y Carvajal, VII marquesa de Arneva (Wandosell 2012: 409).

Además de capital social, los Echeverría aportaron fincas en Orihuela (Alicante) con más de 300 hectáreas. ${ }^{19} \mathrm{El}$ enlace abrió importantes relaciones de parentesco -marqueses de Arneva y condes de Montemar, Roca de Togores, Rossique y marqueses de Ordoño-, con consecuencias económicas y sociales. El sueño duró poco: el 17 de mayo de 1912 el flamante marqués fallecía a los 33 años.

La muerte de Zapata el 16 de julio de 1918 -cuyo entierro fue presidido por Juan de la Cierva y todos los diputados y senadores de la provincia- vino a cerrar un ciclo expansivo de la minería local, coincidiendo con la recesión impuesta por la Primera Guerra Mundial y las crisis encadenadas a partir de entonces, que culminarían en los años 40 (Egea 2014: 187ss).

19 Archivo Central del Ministerio de Agricultura, Pesca y Alimentación [ACMAPAMA]. Libros Registro de la Propiedad Expropiable. Torre Pacheco, Fuente Álamo y Orihuela (1933). 


\section{LOS ZAPATA}

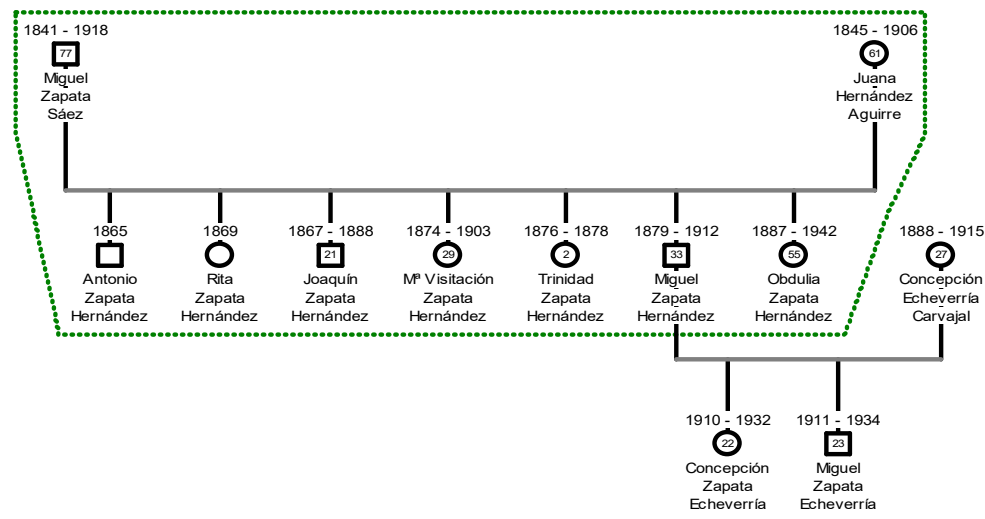

\section{JOSÉ MAESTRE PÉREZ: DE MÉDICO A EMPRESARIO}

Beneficiario del imperio levantado fue José Maestre Pérez, que contrajo matrimonio con las dos únicas hijas de Zapata. En 1913, fallecido su cuñado, fue nombrado administrador de la Mancomunidad Miguel Zapata e Hijos (Sampedro 2021). En 1915, tras la desaparición de su cuñada, la marquesa de Villalba de los Llanos, se hizo cargo de sus dos sobrinos. Toda la herencia quedó bajo su control. En 1918, al morir su suegro, percibió un tercio de todos los bienes, derechos y acciones presentes y futuras (Román 1996: 277).

Había nacido en Murcia, el 31 de agosto de 1866, en el seno de una familia dedicada al despacho de vinos al por menor, una taberna de tercer orden, por la que apenas se tributaba (Martínez Tornel 1887: 22). El tesón de la madre permitió costear los estudios de los tres hijos. Cursó -como sus hermanos- la carrera de Medicina en la Universidad Central de Madrid, licenciándose en el curso 1885/1886 y doctorándose en $1888^{20}$. El 23 de noviembre de aquel año fue nombrado médico municipal, con carácter interino, de la localidad minera de Portmán. ${ }^{21}$ No era un empleo bien remunerado. Con las igualas, podía alcanzar las 1.500 pesetas anuales: una suma idéntica a la que cobraba el cabo de serenos. ${ }^{22}$

${ }^{20}$ El Diario de Murcia, 10 de febrero de 1893.

${ }^{21}$ El Eco de Cartagena, 21 de noviembre de 1888 y Boletín Oficial de la Provincia de Murcia, 13 de enero de 1889.

${ }^{22}$ Boletín Oficial de la Provincia de Murcia, 20 de agosto de 1892. 
Su labor asistencial mereció algunas críticas en relación con "...las curaciones y visitas a los enfermos pobres...”. ${ }^{23}$

El 4 de junio de 1891 -con 25 años- desposó con Visitación Zapata, de 17. Carecía de recursos, pero aportaba capital social, la mejor expresión de la yernocracia. El significado del enlace no pasó desapercibido a sus coetáneos, “... más no fueron sólo las minas basamento de su fortuna, que también el amor contribuyó a su esplendor y aumento [...] mirando al futuro y al pasado, contemplaba con un ojo las gracias de Cleo [hija de Miguel Zapata] y trataba de penetrar con el otro en los tesoros de Lupus" (Albaladejo 1910: 35).

La vía matrimonial lo liberó del trabajo asalariado. El 9 de octubre de 1891, a los cuatro meses de la boda, solicitó del Ayuntamiento de La Unión la rescisión de su contrato. ${ }^{24}$ En enero de 1892, su suegro le confirió poderes para dirigir los negocios fabriles, mineros y comerciales a los que se venía dedicando, cesando en esa representación su anterior apoderado y sobrino Luis Zapata Martínez. ${ }^{25}$ Se reafirmaba de este modo la concepción de empresa familiar del complejo económico de Zapata.

El 8 de junio de 1905, tras enviudar en 1903, celebró segundas nupcias con su cuñada Obdulia, a la que doblaba la edad con holgura. A él le faltaban dos meses para cumplir 39 años, ella tenía 18. La unión evitaba la disgregación del patrimonio de Zapata. Un caso de sororato, en el que además de las cuestiones económicas debieron mediar los sentimientos de la contrayente, involucrada en la educación de los sobrinos. Se trataba de una práctica habitual entre las grandes fortunas. Como señala Pilar Muñoz “... la combinación de intereses materiales y afectos hace que las relaciones familiares se transformen en relaciones económicas y viceversa" (2001: 178).

Entrelazó sus intereses económicos con los de Zapata. Además de la Mancomunidad de Miguel Zapata e Hijos, tuvo participación en el Banco de Cartagena -del que llegó a ser vicepresidente- y en las compañías de seguros, gas, salinas y obras públicas de su suegro, sin olvidar sus intereses compartidos en el Sindicato para el Desagüe de las Minas del Beal, la solución manejada para hacer posible la explotación de una extensa zona inundada de la cuenca minera de Cartagena. En el catastro minero de 1909 aparecía como uno de los grandes

\footnotetext{
${ }^{23}$ El Eco de Cartagena 20 de junio de 1892.

${ }^{24}$ Boletín Oficial de la Provincia de Murcia, 9 de octubre de 1891.

${ }^{25}$ El Eco de Cartagena, 30 de enero de 1892.
} 
propietarios de la provincia, con 720,8 hectáreas, distribuidas entre Mazarrón $(314,3)$, Cartagena (296,7) y Lorca (26) (Egea 1986: 149).

Intervino en el negocio inmobiliario, creando en 1902 -con otros socios- la Constructora Moderna, que adquirió terrenos en el ensanche de Cartagena al objeto de levantar cinco manzanas de edificios. ${ }^{26}$ También en la Sociedad La Conciliación, que planteó la construcción de 163 viviendas en el barrio cartagenero del mismo nombre. Se convirtió en un gran rentista, con propiedades en Cartagena, La Unión y diversos poblados mineros de la comarca. Todo era susceptible de convertirse en dividendo, participando en la ampliación del cementerio de Nuestra Sra. de los Remedios de Cartagena. ${ }^{27}$

En pocos años amasó una gran fortuna. En 1896 era uno de los mayores contribuyentes de La Unión ${ }^{28}$. En 1905 tributaba por los conceptos de minas $(3.548,16)$ y edificios y solares $(578,82)$, lo que representaba una renta anual de $20.634,90$ pesetas $^{29}$. En mayo de 1906 suscribía deuda amortizable por 500.000 pesetas. ${ }^{30}$ En las mismas fechas, por medio de Juan de la Cierva, aportaba 500.000 pesetas para la constitución de la Sociedad Editorial de España, que creaba una importante cadena de periódicos, conocida por El Trust, dirigida por Miguel Moya (Pérez y Gómez 1965: 29), toda una referencia periodística y política del momento. ${ }^{31}$ En 1907, según el periódico $A B C$, era el Rockefeller de Cartagena. ${ }^{32}$ En 1917 figuraba como duodécimo contribuyente de la provincia de Murcia (Sampedro, 2021).

El 31 de mayo de 1921 escrituró la sociedad anónima Contrataciones e Industrias [CISA], dedicada a construcción, venta de carbones, materiales para industrias y suministros. ${ }^{33}$ Tenía su sede en Madrid y contaba con agencias y depósitos en Barcelona, Almería, Cartagena y Valencia. Con un capital inicial de 675.000

\footnotetext{
${ }^{26}$ El Eco de Cartagena, 30 de agosto de 1902.

${ }^{27}$ La Verdad de Murcia, 1 de enero de 1922.

${ }^{28}$ Las Provincias de Levante (Murcia), 14 de octubre de 1896.

29

http://www.senado.es/web/conocersenado/senadohistoria/senado18341923/senadores 1

${ }^{30}$ El Liberal (Murcia), 2 de mayo de 1906.

${ }^{31}$ Centro Documental de la Memoria Histórica, Escrituras de retroventa firmadas por la Sociedad Editorial de España y José Maestre Pérez. PS-MADRID,891,22, 14 de mayo de 1906 - 12 de febrero de 1907.

$32 A B C$ (Madrid), 8 de abril de 1907.

${ }^{33}$ Gaceta Minera y Comercial (Cartagena), 16 de agosto de 1921, p. 261.
} 
pesetas, alcanzó los 10 millones en 1927 (Lorenzo 1989: 531-532; López-Morell 2011: 17).

Se interesó por la agricultura, concentrando su inversión en el Campo de Cartagena, desarrollando el regadío por medio de pozos artesianos, lo que revalorizó sus tierras. ${ }^{34}$ Según el Registro de la Propiedad Expropiable publicado en 1933 controlaba una superficie de 1.887,14 hectáreas, distribuidas en 174 fincas, de diversas calidades y cultivos, algunas con casas de labranza, molino, balsa, aljibe, almazara, noria, pozo y pajares. Destacaba la Casa Grande, la hacienda emblemática de Miguel Zapata Sáez en San Javier. ${ }^{35}$ El 57,6\% de aquellas propiedades había sido recibido por herencia, incluida la de los sobrinos Zapata Echevarría. La compra representaba un porcentaje nada desdeñable, lo que apunta a la diversificación de activos en momentos de recesión minera, como estaban haciendo otros empresarios del sector (Román 1993: 141). Fue designado vocal de la Confederación Sindical Hidrográfica del Segura, de la que era presidente Cierva y secretario el marqués de Rozalejo ${ }^{36}$. Allí alternaría con los terratenientes más relevantes de la provincia.

Las relaciones sociales fueron determinantes para la política y los negocios (Pro 1995: 69). Maestre, un recién llegado entre los privilegiados, buscó integrarse en la sociedad burguesa de su tiempo, formando parte de sus círculos empresariales, de sus espacios de ocio y de sus grupos de presión. Formó parte de un sinfín de comisiones, en los que ampliaba su nivel de relaciones sociales y económicas. Acaparó cargos y representaciones en Cartagena: vocal-patrono de la Junta de Reformas Sociales ${ }^{37}$, miembro de la junta directiva de la Cámara de Comercio, representándola en congresos y asambleas nacionales; de la Sociedad Económica de Amigos del País; presidente de la Junta de Obras del Puerto entre 1901 y 1906 y de la Cámara Minera, saltando a la comisión permanente de la Unión Minera de España, presidida por el marqués de Comillas ${ }^{38}$. Alternaba en el Casino, en el Ateneo Mercantil e Industrial y en el Club de Regatas, otras tantas fronteras sociales. A ello se añadía la sociabilidad informal presente en sus relaciones privadas, necesarias en los arreglos matrimoniales (Muñoz 2001: 80), fundamentalmente bodas, bautizos y entierros, cuyos asistentes eran aireados por

${ }^{34}$ El Porvenir (Cartagena), 6 de julio de 1928.

${ }^{35}$ AC-MAPAMA. Libros Registro de la Propiedad Expropiable. Cartagena, Fuente Álamo, Orihuela, Torre Pacheco y San Javier (1933).

${ }^{36}$ Cartagena Nueva, 9 de noviembre de 1927.

${ }^{37}$ El Eco de Cartagena, 12 de enero de 1907.

${ }^{38}$ El Diario de Murcia, 9 de enero de 1901. 
la prensa, subrayando la menor o mayor categoría de las familias que estaban detrás.

No descartó las obras de caridad ni la religiosidad de relumbrón, haciendo ostentación de sus creencias con solemnidad y dispendio, actuando de mecenas de la Iglesia, financiando obras, monumentos, fiestas patronales, procesiones y coronaciones de vírgenes; bendiciendo sus moradas y entronizando en las mismas el Sagrado Corazón de Jesús: señas de identidad de aquella clase a la que quería imitar (Artola 2015: 85-90).

Un pensamiento católico conservador que se tradujo en un paternalismo social con la creación de centros de beneficencia, sociedades obreras, entregas de casas y fiestas de confraternización con los empleados, como la Fiesta del Taller, donde se resaltaban los valores del patrono. Una filantropía propia de las clases altas, que consideraban a la caridad como el mejor lenitivo a las contradicciones de clase. Su concepto del societarismo obrero no ofrece dudas, una clase sumisa y alejada de toda conflictividad, mostrándose partidario de crear "... un Círculo de Artesanos, de Obreros, donde encuentren éstos distracción culta y sana, donde de verdad no se haga política, de donde se irradie la luz fecunda y redentora para nuestro proletariado". ${ }^{39}$

Respaldó el sindicalismo católico, concretado en la sociedad de obreros La Legalidad, establecida en Portmán el 7 de marzo de 1918, cuya afiliación era obligatoria para trabajar en sus fábricas y minas. Un sindicato rompehuelgas que, por su carácter contrarrevolucionario, fue conocido como La Chapa. El 31 de enero de 1919, dio vida a la sociedad se socorros mutuos La Maquinista de Levante y el 3 de noviembre de 1920 a un economato dependiente de la Legalidad. Las iniciativas buscaban contrarrestar la extensión del movimiento obrero y el auge de la conflictividad en la sierra minera (Vilar, Egea y Victoria 1987: 184-190, 239-242 y 317-328).

El salto cualitativo en la escala social se percibió en el tratamiento recibido de Excmo. Sr., extensible a sus consortes. Miguel Zapata y su mujer no pasaron de Don y Doña. Ascenso que se reflejaba en los consumos suntuarios. Moradas de lujo, automóviles, yates, viajes y fincas de recreo. Una exhibición del progreso logrado. Residencias levantadas con la firma de reputados arquitectos, como la de Víctor Beltrí, una de las cumbres del modernismo levantino (Pérez Rojas 1986). A él se debió la Casa Grande de Portmán, que habitó Miguel Zapata Sáez, y la Casa Zapata de Cartagena, destinada a su hijo Miguel, con toda clase de

${ }^{39}$ El Liberal (Murcia), 10 de marzo de 1915. 
comodidades y lujos. ${ }^{40}$ Maestre exteriorizó su poder con la construcción en 1906 de una gran mansión en Cartagena. El modernismo se convirtió así en expresión de la burguesía cartagenera. Siguiendo a Bourdieu, en la legitimación de su dominación por medio del poder de su proyección simbólica (1998: 247).

\section{LOS MAESTRE Y LA POLÍTICA}

Los Maestre procedían de Monóvar (Alicante). En 1864 el matrimonio formado por Tomás Maestre Berenguer y Francisca Pérez Asensio se trasladó a Murcia. Le sobrevivieron tres hijos: Tomás (Monóvar, 1857- Madrid, 1936), José (Murcia, 1866 - Madrid, 1933) y Ponciano (Murcia, 1868 - La Unión, 1936). Los tres cursaron la carrera de Medicina y, con diferente grado de compromiso, entraron en política, reiterándose sus designaciones por la provincia de Murcia, subrayando el respaldo de que gozaban y el sólido cacicazgo que los arropaba. (Rey y Moreno 1996: 193-195). A partir de 1919, a aquella cohorte, se sumó el primogénito de José.

Formaron parte de los partidos dinásticos. José pasó sin muchos problemas del Liberal al Conservador, en tanto Tomás se mantuvo en el Liberal y Ponciano y el hijo del primero en el Conservador. Constituyeron una auténtica saga de senadores y diputados, en sintonía con la endogamia política de la época (Peña 1997: 420). Como ha señalado Moreno: “... más que amigos políticos podría hablarse de familias políticas” (1998: 190-192). En expresión de Jorge Luengo: "familias políticas que patrimonializaban el poder y la influencia" (2016: 98).

Se integraron en la elite política de la Restauración, formada por no más de un millar de individuos (Cabrera y Rey 2002: 73). Entre 1905 y 1923 tomaron asiento en las Cortes de forma ininterrumpida y, salvo en la legislatura de 19111914, lo hicieron en ambas sedes parlamentarias. A partir de 1919 coincidieron tres de ellos en las dos cámaras. Los de mayor presencia fueron Tomás (once legislaturas, diez de ellas como senador) y José (diez legislaturas, seis como diputado), siendo además ministro en dos Gobiernos, senador vitalicio y Gobernador del Banco de España. Por su parte, José Maestre Zapata fue diputado en tres convocatorias y Ponciano en dos, además de gobernador civil de Albacete (1917-1918), Málaga (1919), Tarragona (1921) y Cádiz, en tres ocasiones: 1919, 1921-1922 y 1931.

\footnotetext{
40 Archivo Municipal de Cartagena. Licencia de obra concedida a Miguel Zapata Hernández para construir un hotel en la manzana nº. 1 del Ensanche. 1910.
} 
José Maestre Pérez fue el de mayor recorrido, aunque no era un político nato, dadas sus discutidas dotes parlamentarias: "Como orador, si no de brillante elocuencia, sí de convincente forma..." "41. Dominó la circunscripción cartagenera, donde sus intereses económicos y sus relaciones familiares le proporcionaron una red clientelar, conectada primero a Romanones y después a Cierva. Ejerció un poder sin contrapeso posible. Lo subraya el escritor unionense Pedro García Valdés, que apuntaba a las bases de su preeminencia: “... a través de una prensa adicta y de los jefes y jefecillos que acudían a su despacho a rendirle pleitesía" (1966: 48). Pudo contar con dos periódicos a los que financiaba: Las Provincias de Levante en Murcia y El Eco de Cartagena. Favores políticos, corrupción y amaño electoral fueron sus mimbres. ${ }^{42}$ Una fortuna capaz de comprar voluntades, incluidas las más ajenas a su ideario, llegando a componendas con los adversarios políticos (Egea 1990). No faltó la violencia, con denuncias que llegaron al Congreso de los Diputados. ${ }^{43}$

En las redes clientelares aparecía un núcleo reducido de personas vinculadas al cacique por relaciones de parentesco y amistad, en un segundo círculo los dependientes por los favores recibidos y finalmente los clientes colectivos, las asociaciones económicas o profesionales, igualmente agradecidas por las atenciones obtenidas (Cruz 1999: 112-113). El antedespacho de Maestre era un buen ejemplo de lo dicho:

\begin{abstract}
Hemos saludado a muchos señores, viejos conocidos. Son amigos, correligionarios, íntimos del jefe. Políticos, mineros, comerciantes, pretendientes. Todo un enjambre social del profuso panal político. No faltan, naturalmente, algunos zánganos. Seamos sinceros; bastantes. Aparte de su asunto personal, todos llevan una noticia, un comentario, una interrogación o un horóscopo relacionado con la política ${ }^{44}$.
\end{abstract}

Se ajustó a los itinerarios establecidos en el cursus honorum del momento, labrando su futuro paso a paso: de alcalde a ministro (Tusell 1976: 34; Cuenca y Miranda 1992: 117). La primera parte de su carrera política la hizo en las filas del Partido Liberal, impulsado por Romanones, con activos mineros y financieros en la comarca, sin menospreciar los electorales, y con el que su suegro y él mismo

${ }^{41}$ La Nación (Madrid), 27 de marzo de 1933.

${ }^{42}$ Diario de las Sesiones de las Cortes. Congreso de los Diputados, sesión del 9 de marzo de 1912, pp. 2.833-2.835.

${ }^{43}$ Diario de Sesiones de las Cortes, 7 de noviembre de 1906, pp. 3.681-3.682.

${ }^{44}$ El Liberal (Murcia), 10 de marzo de 1915. 
mantenían estrechas relaciones económicas (Chastagnaret 1993: 123-137). Desde 1893 fue su hombre de La Unión, alcanzado la jefatura local del partido en 1895 y realizando un fulgurante ascenso: alcalde de la localidad minera (1897-1899), diputado provincial (1901-1905), presidente de la Diputación (1901), jefe de los liberales de Cartagena y senador (1905-1906).

La promoción tenía un precio. Aparece en la carta que Maestre, como presidente de la Junta de Obras del Puerto de Cartagena, remitió a Romanones el 17 de septiembre de 1902, comunicándole que el grueso de los fondos que la entidad tenía depositados en el Banco de España sería ingresado en el Banco de Cartagena, fundado por el conde, Con ello quería: “... poder demostrarle con hechos, que le está profundamente agradecido su leal amigo". ${ }^{45}$

En febrero de 1906 saltó al Partido Conservador, renunciando a su acta de senador. El padrinazgo de Cierva -abogado de la familia, con el que además compartía negocios- resultó decisivo en el giro. ${ }^{46}$ Maestre se conectó de este modo a una de las principales redes caciquiles de España (Egea 1990: 175-240; 2015: 159-192 y Ruiz 1991). Cierva, que representaba el sector más reaccionario del Partido Conservador, contó con él para formar su estado mayor (Cierva 1955: 152-159). La operación le permitió intervenir la totalidad de la provincia de Murcia, desplazando a Antonio García Alíx, que hasta entonces controlaba la circunscripción cartagenera (Buireau 1990: 357).

De la mano de Cierva alcanzó la cima de su carrera política. Por su mediación, el 17 de abril de 1919, fue nombrado ministro de Abastecimientos. ${ }^{47}$ En el momento de su designación tenía 53 años, un poco por debajo de la edad en la que se accedía a aquel puesto (Cuenca y Miranda 1998: 18). Desempeñó el cargo durante tres meses, hasta el 20 de julio. ${ }^{48}$ Por Real decreto de 1ㅇ de junio de 1919 fue investido senador vitalicio. Los elegidos en aquella ocasión eran casi todos amigos y parientes de Maura y Cierva (Soldevilla 1920: 193-194). Entre el 17 de marzo y el 23 de agosto de 1921 ejerció el cargo de Gobernador del Banco de España. ${ }^{49}$ El 14 de agosto de 1921 ocupó el Ministerio de Fomento en un nuevo

${ }^{45}$ Real Academia de la Historia. Archivo Romanones. Leg. 07/25. Carta de Maestre a Romanones sobre la Junta del Puerto de Cartagena, 17 de septiembre de 1902.

${ }^{46}$ AHN, FC-Tribunal_Supremo_Civil, 289, Exp. 212; 868, Exp. 269; 868, Exp. 288; 246, Exp. 327; 536, Exp.378; 331, Exp. 388; 272, Exp. 45; 339, Exp. 568 y 500, Exp. 881.

47 Gaceta de Madrid, 18 de abril de 1919, p. 226.

${ }^{48}$ Gaceta de Madrid, 21 de julio de 1919, p. 270.

49 Gaceta de Madrid, 18 de marzo de 1921, p. 910 y 26 de agosto de 1921, p. 830. 
gobierno de Maura, con Cierva en Guerra. ${ }^{50} \mathrm{El}$ gabinete cayó el 8 de marzo de 1922. Finalmente, el 27 de junio, -en calidad de ex ministro-, fue distinguido como consejero de Estado por Hacienda para el bienio de 1922-1924. ${ }^{51}$

\section{POLÍTICA Y GANANCIA ECONÓMICA}

La política y la economía resultaron indisociables, con acreditados "vasos comunicantes" (González Portilla 1994: 97-135 y Larraza 2002: 298). La primera servía para asegurar, fortalecer y ampliar los rendimientos de la segunda, lo que puede definirse de caciquismo empresarial dentro del patronazgo urbano (Díaz Morlán 2000: 118 y Sierra 1990: 143-158). Numerosos nombres de políticos de la etapa respaldan la afirmación (Tuñón 1967: 78-83). Maestre fue uno de ellos.

El 13 de noviembre de 1905, recién llegado al Senado, presentó una proposición de ley para otorgar a su cuñado -Miguel Zapata Hernández- la concesión de un ferrocarril de vía estrecha en la provincia de Murcia: de Totana al puerto de Mazarrón, con ramales a las minas de la zona. Debía declararse de utilidad pública para los efectos de expropiación forzosa y ocupación de terrenos de dominio público. Una nota manuscrita, -que no pasó al Diario de Sesionesdejaba al descubierto el modus operandi de la Cámara Alta: "Sería conveniente, dado el criterio en que viene inspirándose el Senado, que no se personalizase la entidad a la que hubiese de otorgarse la concesión". ${ }^{52}$

Su labor parlamentaria se ciñó a la defensa de las utilidades mineras, que es decir tanto como las suyas propias, oponiéndose al monopolio de explosivos, abogando por la reforma de la tributación minera y la supresión de derechos arancelarios que pesaban sobre la actividad, consiguiendo mejoras para la ensenada de Portmán -donde estaban sus embarcaderos- y solicitando la reversión al Estado de los muelles particulares de Cartagena, que dificultaban el tráfico portuario. Aquella relación se hizo tan evidente que la prensa de la oposición no tardó en resaltarla: “... tiene la política como un complemento o defensa de sus intereses, de sus negocios [...] Es uno de esos industriales o negociadores que necesitan de la política para sus asuntos". ${ }^{53}$

${ }^{50}$ Gaceta de Madrid, 15 de agosto de 1921, p. 727.

${ }^{51}$ Gaceta de Madrid, 28 de junio de 1922, p. 1.101.

52 Diario de las Sesiones de las Cortes. Senado, Sesión de 11 de noviembre de 1905. Apéndice 20.

${ }^{53}$ La Tierra (Cartagena), 19 de septiembre de 1911. 
Obtuvo la concesión de obras públicas, una de las formas probadas de interacción de la política en la economía (Piqueras 1998: 42-43). Consiguió contratas millonarias para la empresa familiar: desde puentes y carreteras en Málaga a diques en Valencia, Barcelona, Tarragona y Vinaroz..$^{54}$ El caso más escandaloso se dio en el puerto de Valencia, cuya adjudicación consiguió en 1911. El pliego de condiciones expresaba los trabajos anuales que debían efectuarse, produciéndose toda suerte de irregularidades al amparo de la Gaceta de Madrid: "... dieron en llover Reales órdenes alterando en beneficio del contratista los términos de lo convenido". 55

El carácter clientelar de su gestión se tradujo en la atención a demandas locales, consiguiendo la aprobación de algunos caminos vecinales para paliar el desempleo, un recurso habitual en tiempos de crisis. ${ }^{56} \mathrm{El}$ resultado servía para ampliar las bases del consenso social (Cabrera y Rey 2002: 73-75). Gestiones aireadas por la prensa y transubstanciadas en apoyo electoral y mediación con el poder central, adquiriendo una función representativa (Sierra 2000: 14-15). La práctica -conocida en el argot de la época como carreteras parlamentarias-, asentada en el favor privado, iba en detrimento de la planificación nacional (Moreno Luzón 1996: 184-185). Lo esperado en aquella España donde nada se hacía sin la influencia del cacique.

En el programa a desarrollar como ministro de Abastecimientos introdujo cuestiones mineras, muy alejadas de sus responsabilidades. ${ }^{57}$ Una actuación repetida como senador vitalicio. ${ }^{58}$ Miras excesivamente particulares, como hizo notar el senador Bas, de la comisión permanente de Hacienda: “... el Sr. Maestre habla generalmente de las cuestiones mineras mirando sólo a aquello que ocurre en su región". ${ }^{59}$ Como ministro de Fomento, por Real decreto de 23 de septiembre de 1921, creó las Cámaras Mineras, de colegiación obligatoria para los dedicados a aquella industria. Podían establecerse en lugares donde ya existían

${ }^{54}$ La Correspondencia de España (Madrid), 12 de octubre de 1911, Madrid Científico, 1911, p. 16, Diario de Valencia, 29 de junio de 1913 y La Correspondencia de Valencia, 19 de marzo de 1913.

${ }_{55}$ Madrid Científico, 1918, p. 10.

56 El Tiempo (Murcia), 3 de septiembre de 1914 y El Liberal (Murcia), 21 de septiembre de 1914.

${ }^{57}$ La Época (Madrid), 24 de abril de 1919.

${ }^{58}$ Diario de las Sesiones de las Cortes. Senado, sesión del 17 de marzo de 1920, p. 1.900

${ }^{59}$ Diario de las Sesiones de las Cortes. Senado, sesión del 27 de marzo de 1920, p. 2.096 . 
sindicatos de productores de minerales, como eran los casos de Linares y Cartagena. ${ }^{60}$ Dictó un nuevo reglamento y plan de Estudios de la Escuela Especial de Ingenieros de Minas. ${ }^{61}$ En fin, dio vida a la Dirección General de Minas, Metalurgia e Industrias Navales. ${ }^{62}$

\section{ESTRATEGIAS MATRIMONIALES}

José Maestre apostó por una familia extensa: un total de 13 hijos, habidos entre 1891 y 1923. En 12 años tuvo cinco con su primera esposa (Visitación), un alumbramiento cada 28 meses. Con la segunda (Obdulia), ocho en 18 años: un parto cada 27 meses, el último doble. Para las clases altas, una estirpe numerosa era signo de poder y la posibilidad de ampliar vínculos económicos y sociales. Tal pulsión reproductora vendría también inducida por el deseo de perpetuar el apellido y el temor a quedarse sin descendencia, lo que podía afectar al patrimonio acumulado. Tenía el ejemplo de sus suegros, que vieron desaparecer a la mayoría de sus hijos, resultando especialmente dramática, dada la concepción patrilineal imperante, la pérdida de su último varón. En el mismo sentido, patrocinó una familia compleja, propia de las clases altas (Reher 1996: 67). Según el padrón municipal de 1921 el matrimonio Maestre-Zapata habitaba en Cartagena con ocho de sus hijos -entre 1 y 19 años-, sus dos sobrinos ZapataEchevarría, de 9 y 10 años; cinco sirvientas y los dos porteros.

La educación de los hijos atendió a la considerada adecuada a sus fines matrimoniales y económicos. Las hijas estudiaron en el Colegio de San Miguel de Cartagena y más adelante como alumnas internas del Colegio Inglés de Santa Isabel en Madrid, pasando al colegio matriz en Londres ${ }^{63}$. Los varones cursaron estudios superiores con estancias en el extranjero. Criados entre algodones, soldados de cuota en medio de la Guerra de Marruecos, sin que faltaran los indicadores de distinción: regatas, coches deportivos y viajes por Europa y Norteamérica. Asimismo, menudearon los escándalos relacionados con los modos y maneras de conducirse los potentados, derivados del desenfreno y el engreimiento. ${ }^{64}$

${ }^{60}$ Gaceta de Madrid, 24 de septiembre de 1921, pp. 1.219-1.221.

${ }^{61}$ Gaceta de Madrid, 19 de diciembre de 1921, pp. 946-954.

${ }^{62}$ Gaceta de Madrid, 23 de febrero de 1922, pp. 812-815.

${ }^{63}$ La Verdad de Murcia, 24 de junio de 1921 y 24 de octubre de 1926.

${ }^{64}$ La Nación (Madrid), 19 de abril de 1929. 
La estrategia matrimonial buscó, en la línea planteada por tantos otros burgueses, conservar e incrementar el patrimonio familiar (González Portilla 1992: 143176). Al margen de las decisiones personales, salta a la vista que en el caso que nos ocupa hubo enlaces concertados. En 1894 tuvieron lugar las segundas nupcias de su padre, Tomás Maestre Berenguer, -viudo desde el año anterior-, con María Hernández Aguirre, hermana de su suegra, que también había perdido a su marido, conciliando intereses de sendos linajes y reforzando el parentesco como práctica de reproducción de los grupos privilegiados. La yernocracia fue otro de los recursos. En esa dirección caben enmarcar los esponsales celebrados el 7 de enero de 1914 entre la hija mayor -Visitación- y Juan Rubio de la Torre, once años mayor que ella, cuando por entonces la diferencia de edad entre los cónyuges era de tres años y medio (Cachinero 1982: 92-93). El novio, ingeniero de minas, venía demostrando su cualificación como director general de la Mancomunidad Miguel Zapata e Hijos, lo que garantizaba la gestión del buque insignia del negocio familiar. ${ }^{65}$

La tercera actuación se sustentó en el deseo de mejorar la situación de la familia mediante el entronque con apellidos de raigambre, una conducta habitual entre notables, cuyos árboles genealógicos tendían a entrelazarse generación tras generación. Se apostó por la boda del primogénito. El 30 de abril de 1917 José se vinculó a Florentina Aznar Pedreño, hija de Justo Aznar Butigieg, que había dejado el Ejército tras unirse a Florentina Pedreño Deu, heredera de una de las fortunas mineras más importantes de la provincia, para convertirse en empresario y pisar la arena política: diputado a Cortes por Cartagena en 1891 y senador por Murcia entre 1893 y 1905. Florentina Aznar era además sobrina del teniente general Ángel Aznar, diputado por Murcia (Lorca y Cartagena) en nueve legislaturas -entre 1896 y 1907-, Jefe del Cuarto Militar de S.M. y ministro de la Guerra con Canalejas en 1910. La novia aportó al matrimonio extensas propiedades agrarias en Totana (Murcia). La unión permitió emparentar con los condes de Casa Valiente -sus cuñados-, alternando por aquella vía con el marqués de Ordoño y la condesa de Alcudia y de Gestalgar. ${ }^{66}$ Con menor relieve, Tomás -el segundo hijo varón- se unió el 9 de enero de 1924 a Carmen Ballester Fernández, hija de un consignatario de buques de Cartagena.

No todos los casamientos pudieron aspirar a aquel objetivo, teniendo que recurrir a la clase media, abundando en la yernocracia como forma de asegurar el futuro de las hijas. Francisca casó el 1o de marzo de 1920 con Lorenzo Morales

${ }^{65}$ El Eco de Cartagena, 8 de enero de 1914.

${ }^{66}$ El Eco de Cartagena, 29 de agosto de 1919. 
Parra, dos años menor, ingeniero de la Junta de Obras del Puerto de Cartagena, de la que Maestre había sido director. Por su parte, Juana lo hizo el 10 de diciembre de 1930 con José López Palazón, ingeniero agrónomo.

Las nupcias celebradas durante los años de la II República fueron un reflejo de la situación de la familia, asediada por problemas económicos y en franco retroceso político. Se recurrió a la endogamia, con las oportunas dispensas eclesiásticas (Lanzinger 2017: 423). Un uso extendido entre las élites industriales españolas (Díaz Morlán 2002: 315-330). El 25 de abril de 1932, Miguel Maestre Zapata tomó estado con su prima Concepción Zapata Echeverría ${ }^{67}$. El 27 de julio de 1934, lo hizo Obdulia Maestre Zapata con su también primo Miguel Zapata Echeverría, convertido en marqués de Villalba de los Llanos a la muerte de su madre. En ambos casos habían crecido bajo el mismo techo (Lorenzo 1989: 19). Lo curioso es que en marzo de 1931 Obdulia había ingresado en el Noviciado de Esclavas del Sagrado Corazón de Jesús en Azpeitia (Guipúzcoa). ${ }^{68}$ La otra opción fue vincularse a nuevos ricos, sin el lustre ni la pátina del tiempo. El 24 de junio de 1935 Joaquín enlazó con Ana Ma Bernal Casanova, hija de Juan Bernal Gallego, de la firma murciana Industrias Bernal, dedicada a la fabricación de jabones, embutidos y conservas de carne. ${ }^{69}$

Tras la Guerra Civil, la pérdida de relevancia económica conllevó himeneos de menores pretensiones. El 13 de junio de 1940 Antonio contrajo matrimonio con Ma Dolores Aguilar Ester, hija de un funcionario del Cuerpo Técnico de Inspección Mercantil de Seguros y miembro del consejo de administración de Los Previsores del Porvenir, una asociación mutua de ahorro. Se repitió la inercia endogámica. El 16 de junio de 1941 Francisco Javier Maestre Zapata, hijo de la segunda mujer de Maestre, se unió a Visitación Maestre Aznar, nieta de la primera esposa, a la que llevaba diez años, en la línea de argumentación del papel desempeñado por el parentesco (Lorenzo 1989: 37).

No descartaron maridajes con representantes del régimen franquista. El 15 de enero de 1948 Juan se unió a Angelines Torres Lanzarote, hija del presidente de la Cámara de la Propiedad Urbana de Murcia y vicesecretario de Obras Sindicales. ${ }^{70}$ Mayor aspiración le cupo a Lorenzo, que lo hizo el 19 de julio de 1951 con Encarna Ortuño García, de la buena sociedad oriolana. ${ }^{71}$ Finalmente, el

\footnotetext{
${ }^{67}$ Ahora (Madrid), 26 de abril de 1932.

${ }^{68}$ La Verdad de Murcia, 27 de marzo de 1931.

${ }^{69}$ Levante Agrario (Murcia), 25 de junio de 1935.

${ }^{70}$ Línea (Murcia), 16 de enero de 1948.

${ }^{71}$ Línea (Murcia), 25 de octubre de 1951.
} 
4 de octubre de 1952, Alfonso casó con Ma Carmen Pascual Martínez, hija de un cirujano dentista de Murcia, bien relacionado con la dictadura.

LOS MAESTRE ZAPATA
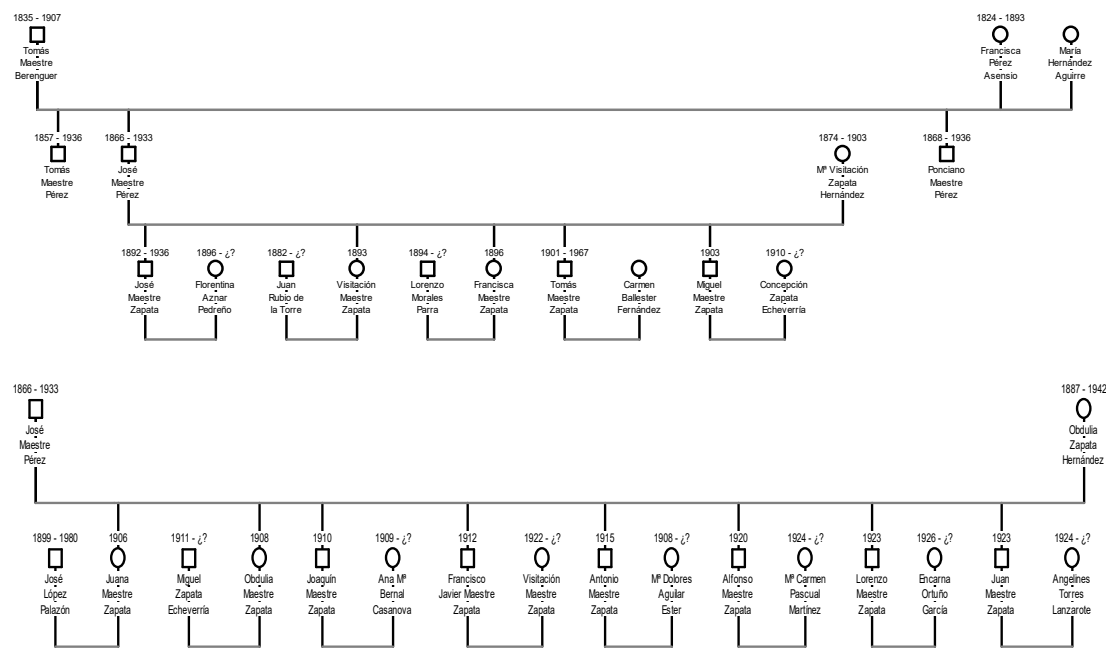

\section{EPÍLOGO: TOMÁS MAESTRE ZAPATA}

A partir de los años 20 una serie de factores provocaron el ocaso de los Maestre. De un lado, la pérdida de hegemonía política, iniciada con la dictadura de Primo de Rivera que cortocircuitó su influencia política. Durante la II República desaparecieron de los centros de decisión y de las directivas de los círculos sociales de Cartagena. Conservaron su relación con San Javier, que fue su cuartel de invierno y, llegado el momento, su centro de conspiración contra la República. Allí mantuvieron su preeminencia, hasta que la tensión suscitada por sus renovados manejos electorales obligó al patriarca a huir a Madrid el 31 de mayo de 1931, "para salvar tal vez su vida"..$^{72}$ Ya no regresaría, falleciendo en la capital el 26 de marzo de 1933 (Fuentes Gómez 2016: 36). La Guerra Civil fue el canto de cisne de la familia.

\footnotetext{
72 Archivo Municipal de San Javier [AMSJ], Acta Capitular, 30 de julio de 1931.
} 
La recesión económica fue paralela a la declinación de su influencia política. El Banco de Cartagena, en el que la familia tenía una importante participación, fue absorbido por el Banco Central. La larga crisis minera empujó a firmar en septiembre de 1930 una fusión con la Compañía Metalúrgica de Peñarroya, aportando la Mancomunidad Miguel Zapata e Hijos la mayoría de los bienes y negocios, alumbrándose la Sociedad Minero-Metalúrgica Zapata Portmán con un capital de 26 millones de pesetas, repartido al 50 por ciento (Prego 2019; LópezMorell 2003: 118-199 y 2016: 337). En el consejo de administración, presidido por Maestre, figuraban sus hijos José, Tomás y Miguel, y su yerno Lorenzo Morales Parra. Con ellos, los Figueroa y los capitalistas franceses ${ }^{73}$.

La declaración de la renta presentada en 1933 por los herederos de Maestre permite aproximarnos a la situación económica de la familia. Los ingresos procedían fundamentalmente de los capitales (92.023,56 pesetas), quedando muy por detrás los bienes inmuebles (21.035,75 pesetas) y las explotaciones agrícolas y ganaderas (10.395,64 pesetas). En total 123.454,95 pesetas. No había ingresos procedentes de las explotaciones mineras ni de los negocios industriales y comerciales. Los signos externos de riqueza también se tenían en cuenta. De un lado, la propiedad de tres automóviles: Lincoln, Ford (ómnibus) y Citroën. De otro, el servicio doméstico: un varón y ocho mujeres. Realizadas las oportunas deducciones y revisiones, el total de los ingresos alcanzaba las 135.552,95 pesetas. $^{74}$

A partir de la II República Tomás Maestre Zapata encarnó la cara visible de los Maestre, en tanto su hermano José se ocupó de los negocios, dejando constancia de su talante, negándose a dar trabajo a los obreros sindicados e incumpliendo la legislación laboral aprobada entonces ${ }^{75}$. En 1933 ingresó en el Partido Agrario Murciano, una formación en la que se integraron los monárquicos alfonsinos. Bajo estas siglas, dentro de la candidatura de la Unión de Derechas, se presentó a las elecciones de diputados a Cortes convocadas para el 19 de noviembre de aquel año. ${ }^{76}$ En la campaña electoral utilizó el nombre de su padre para resucitar viejas adhesiones $^{77}$. Salieron a relucir tretas caciquiles, como el reparto de socorros a los

\footnotetext{
${ }^{73}$ El Eco de Cartagena, 24 de septiembre de 1930 y Revista Ilustrada de banca, ferrocarriles, industria y seguros (Madrid), 10 de enero de 1931.

${ }^{74}$ AHN. Expediente de la Contribución general sobre la Renta de Herederos de José Maestre Pérez correspondiente al ejercicio económico de 1933.

${ }^{75}$ AMSJ, Correspondencia alcaldía. Año 1932.

${ }^{76}$ La Verdad de Murcia, 4 de noviembre de 1933.

${ }_{77}$ Cartagena Nueva, 28 de noviembre de 1933.
} 
obreros parados de La Unión. ${ }^{78}$ Su pensamiento político quedó de manifiesto en el mitin organizado el 5 de noviembre de 1933, donde se erigió en defensor de la religión, la patria y la familia. No le faltó majeza, buscando el enfrentamiento con las izquierdas: "Nos encontrarán donde sea preciso". ${ }^{79}$ Tuvo que concurrir a la segunda vuelta, fijada para el 3 de diciembre, en la que la CEDA y el Partido Republicano Radical pactaron una candidatura conjunta, la denominada Coalición Antimarxista. Esa fue la razón de su acta de diputado (Gil 2006: 283).

En septiembre de 1934, para reforzar su carrera política, adquirió la propiedad del periódico Levante Agrario, que dejó constancia de su tibieza republicana: “... defenderá a la República con un tono moderado". ${ }^{80}$ Se atuvo desde entonces a sus directrices. Fue incendiado el 20 de febrero de 1936, tras el triunfo del Frente Popular, dejando de publicarse a partir de entonces (Checa 1989: 171).

Tuvo una apreciable actividad parlamentaria. Sus intervenciones se centraron en temas locales, siempre con provecho particular. Volcado en el negocio salinero, requirió para todas las explotaciones los mismos beneficios que gozaban las de Torrevieja, de carácter estatal. ${ }^{81}$ También dejó sentir el peso de sus intereses cuando solicitó para los minerales de hierro y plomo su excepción en el incremento de las tarifas ferroviarias. ${ }^{82}$

En noviembre de 1935 ingresó en la CEDA. Bajo sus siglas se presentó a las elecciones generales convocadas para el 16 de febrero de 1936, formando parte de la candidatura de la coalición contrarrevolucionaria. La campaña fue intensa, pero no consiguió los votos necesarios.

Su última acción fue participar en la conspiración contra la República, financiando la compra de armas ( $\mathrm{D}$ [omínguez] Benavides 1976: 15-32 y Martínez Leal 1993: 164-166). Su intervención aparecía en la causa abierta por rebelión a los sumariados de San Javier. ${ }^{83}$ Utilizó su red clientelar, que lo secundó con la ciega obediencia de aquellas tramas, como informó el fiscal y corroboraron los testigos de cargo: “... que todos los procesados son maestristas [...] Todos ellos siguen a Maestre. Si este es fascista, ellos son fascistas y si es comunista, también

${ }^{78}$ La Verdad de Murcia, 17 de noviembre de 1933.

${ }^{79}$ La Verdad de Murcia, 7 de noviembre de 1933.

${ }^{80}$ Levante Agrario (Murcia), 16 de septiembre de 1934.

${ }^{81}$ Diario de Sesiones. Congreso de los Diputados, sesión del 16 de septiembre de 1935, pp. 7.573-7.574 y del 24 de octubre de 1935, p. 10.115.

82 Diario de Sesiones. Congreso de los Diputados, sesión del 19 de abril de 1934, p.

2.434 y apéndice $2 \circ$.

${ }^{83}$ El Liberal (Murcia), 11 de octubre de 1936. 
lo son". ${ }^{84}$ Fue condenado a muerte en rebeldía. Sus colaboradores no corrieron la misma suerte, siendo fusilados siete de ellos.

La decantación política y el comportamiento con los trabajadores situaron a los Maestres, como a otros miembros de las elites, en el centro del huracán (Díaz Morlán 2002: 245-266). José Maestre Zapata fue detenido en su finca de Totana el 5 de agosto de 1936 y recluido en la cárcel de San Antón de Cartagena. ${ }^{85}$ Diez días más tarde fue asesinado en la carretera de Murcia junto con otros seis derechistas. ${ }^{86}$ Su tío Ponciano, que había ingresado en la misma prisión el 28 de julio, fue muerto el 26 de agosto en la carretera de La Unión. ${ }^{87}$

El 7 de octubre de 1936 se decretó la expropiación sin indemnización y a favor del Estado de las fincas rústicas pertenecientes el 18 de julio de 1936 a los que hubiesen intervenido directa o indirectamente en el movimiento insurreccional contra la República. ${ }^{88}$ Quedaron afectadas las haciendas de José, Tomás, Alfonso, Joaquín, Antonio y Miguel Maestre Zapata, Obdulia Zapata Hernández y Miguel Zapata Echeverría. ${ }^{89} \mathrm{El}$ argumentario no ofrecía dudas, dejando constancia del posicionamiento de sus titulares contra la República y el abandono de sus explotaciones. ${ }^{90}$ Las incautaciones fueron realizadas por el Frente Popular, llevándose a cabo la firma de las correspondientes actas. Fueron cedidas a la Casa del Pueblo de San Javier, que las entregó a los sindicatos, tanto a la UGT como a la $\mathrm{CNT}^{91}$. Fueron confiscadas sus propiedades urbanas y los talleres tipográficos del diario Levante Agrario. ${ }^{92}$ En fin, asaltadas y desvalijadas sus mansiones. El

${ }^{84}$ El Liberal (Murcia), 10 de octubre de 1936.

${ }^{85}$ AHN, Fc-Causa_General, 1067, Exp.2. Pieza tercera de Murcia. Cárceles y sacas, fol. 84.

${ }^{86}$ AHN, Fc-Causa_General, 1065, Exp. 18. Cartagena (Murcia), fol. 16.

${ }^{87}$ AHN, Fc-Causa_General, 1067, Exp. 2..., fol. 82 y 1.065, Exp. 18..., fol. 15.

${ }^{88}$ Gaceta de Madrid, 8 de octubre de 1936, pp. 236-237.

${ }^{89}$ Gaceta de Madrid, 11 de septiembre de 1937, p. 1.035 y Gaceta de la República, 27 de abril de 1938, p. 552.

${ }^{90}$ Centro Documental de la Memoria Histórica, PS-Madrid, 1517,8. Expedientes de expropiación de San Javier (Murcia) ordenados alfabéticamente de Barnuevo, José María a Soubrier, Alfonso.

${ }^{91}$ Archivo Naval de Cartagena [ANC]. Sumario 2.445. Causa General Frente Popular de San Javier. Rollo 1, fol. 206v.

${ }^{92}$ Archivo General de la Región de Murcia, DIP,3488/86. Expediente de incautación 35/1937. Talleres tipográficos del diario Levante Agrario, de José Maestre Zapata, en Murcia. 
inventario de lo desposeído, empezando por las cuberterías de plata, revela el lujo de aquellas residencias y su nivel de relaciones sociales. ${ }^{93}$

Tomás Maestre pudo eludir la persecución cruzando a territorio nacionalista. En noviembre de 1936 estaba alistado en las filas franquistas como alférez de complemento de Caballería. En enero de 1937 pasó a la Comandancia Militar de Jerez de la Frontera y de allí al Cuartel General de la Sexta División en Burgos. En julio, como teniente, fue habilitado para ejercer el empleo de capitán. ${ }^{94}$ Obtuvo varias cruces y las medallas de la Campaña y del Águila Alemana. ${ }^{95}$

Terminada la guerra regresó a Cartagena como jefe del Grupo Móvil de la Política Militar de Vanguardia, asumiendo un papel protagonista en la represión que siguió, corriendo con los gastos inherentes a la misma: 204.084,10 pesetas, una cantidad respetable para la época. ${ }^{96} \mathrm{Su}$ labor fue ingente. Entre el 10 de abril y el 30 de septiembre de 1939 llevó a cabo 614 detenciones, con 4.500 expedientes, 6.000 fichas propias, 2.300 del SIM republicano, 800 de masones y 5.000 informaciones a juzgados. Los vehículos del servicio recorrieron 269.415 kilómetros. La Casa Zapata se convirtió en sede de aquella Policía, dando cobijo a todo tipo de abusos y torturas (Egea 2011).

La adaptación política de la familia corrió pareja a la nueva realidad. Uno de los hermanos, Alfonso, se alistó en la División Azul. ${ }^{97}$ A través de Tomás, volvieron a controlar la vida municipal de Cartagena. A juicio de Falange, la corporación nombrada el 5 de noviembre de 1946 era obra suya: el alcalde, tres de los seis tenientes de alcalde y nueve de los 14 concejales eran maestristas declarados. Uno de los tenientes de alcalde era su hermano Joaquín, que ya había sido concejal en mayo de 1942 y noviembre de $1945 . .^{98}$ Con los restantes ediles mediaban intereses económicos o eran empleados suyos. Más adelante, su hermano Lorenzo formó parte de la Hermandad de Labradores, dependiente del

\footnotetext{
${ }^{93}$ ANC. Sumario 2.445..., fol. 119r.

${ }^{94}$ Diario de Burgos, 8 de enero de 1937 y Boletín Oficial del Estado, 14 de julio de 1937, p. 2.356.

${ }^{95}$ Hoja del Lunes (Cartagena), 15 de mayo de 1967.

96 Archivo General de Ávila. Cuartel General del Generalísimo. SIPM. Servicios Periféricos. Informe del Destacamento Especial de Cartagena (abril-septiembre 1939). Signatura C. 2959, 1, fol. 5r-v.

${ }^{97}$ El Noticiero (Cartagena), 13 de julio de 1942.

${ }^{98}$ Archivo General de la Administración. Presidencia 51/20676. Informe (anónimo de Falange), s/f.
} 
sindicato vertical y, en tal condición, el 5 de diciembre de 1954 fue designado concejal del Ayuntamiento de San Javier. ${ }^{99}$

Tomás supo sacar partido a sus buenas relaciones con las esferas políticas y militares del régimen franquista, obteniendo adjudicaciones y beneficios, como las referidas a las encañizadas. ${ }^{100}$ No fue suficiente. Desplazado de la gestión económica por su hermano José, fuera de Cartagena y desposeído de sus propiedades durante la Guerra Civil, cuando regresó en 1939 fue incapaz de tomar el pulso a los negocios familiares. A la inercia del pasado se sumaron imponderables estructurales. Una serie de factores acabaron con las bases tradicionales de su poder económico. Ocurrió con la actividad minerometalúrgica, la pesca, las salinas del Mar Menor y las explotaciones agrícolas. Detrás, según los casos, la esterilización de los criaderos mineros y el atraso tecnológico, la intervención turística y la contaminación del medio marino.

Sin descendencia directa, su única respuesta ante la quiebra fue la liquidación del patrimonio familiar, empezando por las mansiones escrituradas en Cartagena. En marzo de 1940 enajenó al Banco Hispano Americano, por 500.000 pesetas, la Casa Maestre y, en diciembre de 1941, la Casa Zapata a las Hermanas Carmelitas por 300.000 pesetas. No parece que fueran buenas operaciones, dadas las dimensiones de los inmuebles y su valor artístico, aunque hay que señalar que el mercado inmobiliario estaba a la baja (Artola 2015: 249-253).

Siguió el remate de los negocios. En diciembre de 1945 saldó CISA (Lorenzo, 1989: 328, 333 y 532). En 1946 traspasó la mitad de la Sociedad MineroMetalúrgica Zapata Portmán a la Sociedad Minero Metalúrgica de Peñarroya. Finalmente, en 1956, transfirió a su sobrino -Tomás Maestre Aznar- sus derechos sobre La Manga norte (López-Morell 2011: 18 y Domínguez 2018: 31). Se acabó de arruinar en 1958 con un negocio de exportación de barita a Venezuela (Lorenzo 1989: 94). Moriría el 15 de mayo de 1967, encarnando el paradigma de las "tres generaciones" (Mcdonogh 1989: 194-197). A partir de La Manga comenzaría una nueva historia, en la que la amistad política continuó siendo primordial.

${ }^{99}$ Línea (Murcia), 6 de diciembre de 1954.

100 Boletín Oficial del Estado, 28 de marzo de 1942, p. 2.214. 


\section{CONCLUSIONES}

La familia Maestre Zapata ocupó un lugar relevante dentro de la oligarquía murciana. El origen de su fortuna arranca de Miguel Zapata Sáez, conocido como El Tío Lobo, un destacado empresario de la sierra minera de Cartagena, cuyas hijas casaron sucesivamente con José Maestre Pérez, quien supo engrandecer el patrimonio heredado recurriendo a la estrategia matrimonial, la diversificación económica en un contexto alcista y el control de los resortes políticos. Los mismos factores arruinarán el imperio levantado: infortunios familiares, reveses económicos y adversidades políticas. Tres generaciones, extendidas entre 1879 y 1958, de diferente significación: acumulación y consolidación bajo la dirección de Miguel Zapata Sáez, expansión con su yerno José Maestre Pérez y debacle con Tomás Maestre Zapata.

De Zapata a Maestre hay un mundo de diferencias. De un poder circunscrito al ámbito local a unas relaciones basadas en la solidaridad de la clase dirigente. Del Don al Excelentísimo. La distancia entre ellos es la que media entre el rico campesino con voluntad empresarial al industrial con visión global, aunque en ambos casos la sobreexplotación de la mano de obra fue una constante.

Asistimos a un continuado intento de aproximarse al estilo de vida aristocrático, asumiendo sus símbolos externos de riqueza. Nuevos ricos que aspiraron a la diferenciación social, frecuentando espacios exclusivos, adoptando determinados patrones de sociabilidad, consumos suntuarios, catolicismo de relumbrón, obras de beneficencia y medida filantropía.

Una de las características fue la importancia otorgada al núcleo familiar, con su correspondiente estrategia educacional y matrimonial, optando por la sucesión indivisa, propiciando según los casos el ennoblecimiento de uno de sus miembros, asegurando el futuro de la empresa y ampliando las relaciones sociales y económicas. Enlaces concertados, aunque tuvieron que adaptarse al estatus social de cada momento. De los Villalba de los Llanos y los Aznar a los Bernal. De las esferas del poder a los charcuteros murcianos, pasando por la clase media, contemplando la yernocracia, sin renunciar a las prácticas endogámicas como mecanismo de defensa.

La historia de la familia se vinculó a la empresa y la empresa a la política. Los Maestre constituyeron una auténtica saga política de senadores y diputados. Entre 1905 y 1923 al menos un miembro de la familia ocupó un escaño parlamentario en alguna de las Cámaras, levantando un cacicato en Cartagena, con las destrezas al uso y la pertinente red clientelar. 
A partir de los años 20 el imperio levantado comenzó a declinar. Contribuyó la radical transformación de la realidad sociopolítica, especialmente durante la Guerra Civil, que puso en riesgo la propia supervivencia de la familia, que perdió todas sus propiedades y a algunos de sus miembros. Una realidad paralela a la debacle de los negocios, imposibles de remontar tras el conflicto bélico, a pesar de sus buenas relaciones con las nuevas autoridades, recurriendo a la liquidación ruinosa de las propiedades familiares. Una de ellas -La Manga del Mar Menordaría pie a que la siguiente generación alumbrase uno de los negocios del momento, aprovechando el boom turístico de los años 60 , donde la especulación y la amistad política volvieron a darse la mano. Pero esta es otra historia.

\section{BIBLIOGRAFÍA}

ALBALADEjO BRAVO, F. (1910): Poncius Imperator. (Su vida y sus crímenes), Cartagena, Sociedad Levantina de Artes Gráficas.

ARIÈS, Ph. (1983): El hombre ante la muerte, Madrid, Taurus.

ARTOLA BLANCO, M. (2015): El fin de la clase ociosa. De Romanones al estraperlo, 1900-1950, Madrid, Alianza Editorial.

BOURDIEU, P. (1998): La distinción. Criterio y bases sociales del gusto, Madrid, Taurus.

BUIREAU GUARRO, J. (1990): Antonio García Alix: Un ministro del regeneracionismo (1852-1911), Madrid, Instituto de Estudios Fiscales.

CABRERA, M. y REY, F. (2002): El poder de los empresarios. Política y economía en la España contemporánea (1874-2000), Madrid, Taurus.

CACHINERO SÁNCHEZ, B. (1982): "La evolución de la nupcialidad en España (1887-1975)”, Revista Española de Investigaciones Sociológicas, 20, pp. 81-100.

CHASTAGNARET, G. (1983): "De Marseille à Madrid, du plomb à la noblesse et au pouvoir d'Etat: la construction de la fortune de la Cada Figueroa", Cahiers de la Méditerranée, 46-47, pp. 123-137.

CHECA GODOY, A. (1989): Prensa y partidos políticos durante la II República, Salamanca, Universidad de Salamanca.

CIERVA PEÑAFIEL, J. (1955): Notas de mi vida, Madrid, Editorial Reus.

CONESA DUELO, J.M. (2019): El Banco de Cartagena. Una entidad pionera que traspasó fronteras, Cartagena, autor. 
CRESPO, A (2000): Historia de la prensa periódica en la ciudad de Murcia, Murcia, Real Academia Alfonso X el Sabio.

CRUZ ARTACHO, S. (1999): “Clientes, clientelas y política en la España de la Restauración (1875-1923)”, Ayer, 36 (1999), pp. 105-129.

CUENCA TORIBIO, J.M. y MIRANDA GARCÍA, S. (1992): "Sociología de los ministros de la Restauración (1902-1931)", Revista de Estudios Políticos, 75, pp. 87-130.

CUENCA TORIBIO, J.M. y MIRANDA GARCÍA, S. (1998): El poder y sus hombres. ¿Por quiénes hemos sido gobernados los españoles (1705-1998)?, Madrid, Actas.

DÍAZ MORLÁN, P. (2000) "Un ejemplo de clientelismo empresarial: la influencia política del industrial Horacio Echevarrieta”, Historia Social, 36, pp. 101-120.

DÍAZ MORLÁN, P. (2002): Los Ybarra. Una dinastía de empresarios (1801-2001), Madrid, Marcial Pons.

DOMínGUEZ, J.L. (2018): La Manga del Mar Menor. Principales proyectos y estructura societaria, Pontevedra, Edlibrix, 2018.

D[OMÍNGUEZ] BENAVIDES, M. (1976): La escuadra la mandan los cabos, México Roca, 1976.

EGEA BRUNO, P.M. (1979-80): "Movimiento obrero y crisis finisecular en el distrito minero de Cartagena (1895-1898)", Anales de la Universidad de Murcia. Facultad de Filosofía y Letras, XXXVIII, 4, pp. 3-27.

EGEA BRUNO, P.M. (1986): El distrito minero de Cartagena en torno a la Primera Guerra Mundial (1909-1923), Murcia, Universidad de Murcia-Ayuntamiento de Cartagena.

EGEA BRUNO, P.M. (1990): La política y los políticos en la Cartagena de Alfonso XIII (1902-1923), Cartagena, Ayuntamiento de Cartagena-Caja de Ahorros del Mediterráneo.

EGEA BRUNO, P.M. (2011): La represión franquista en Cartagena (1939-1945), 2a ed., Murcia, Ministerio de la Presidencia y Memoria Histórica de Cartagena.

EGEA BRUNO, P.M. (2014): "La minería cartagenera: sector clave de la economía regional (1840-1991)”, en NICOLÁS MARÍN, E. (coord.): Historia Contemporánea de la Región de Murcia, Murcia, Editum, pp. 169-205.

EGEA BRUNO, P.M. (2015): "Mata al rey y vete a Murcia. La corrupción de la justicia en la España de la Restauración", Studia Historica. Historia Contemporánea, 33, pp. 159-192. 
FUENTES GÓMEZ, O. (2016): Una década olvidada (I). La República que no fue, autor, s.l.

GARCÍA VALDÉS, P. (1966): Sobre mis pasos. Recuerdo íntimo de La Unión, autor, inédito.

GALLEGO ZAPATA, M. (2008): "Los Zapata, Los Maestre, Barnuevo, el agua y la ganadería en la zona del Mar Menor", Revista Murciana de Antropología”, 15, p. 447-458.

GIL CUADRADO, L.T. (2006): El Partido Agrario Español (1934-1936). Una alternativa conservadora y republicana, Tesis doctoral, Madrid, Universidad Complutense de Madrid.

GONZÁLEZ PORTILLA, M. (1994): “Industrialización y política en la Restauración: la formación de una nueva elite política”, en CARASA SOTO, P. (ed.): Elites. Prosopografía contemporánea, Valladolid, Secretario de Publicaciones Universidad de Valladolid, pp. 97-135.

GONZÁLEZ PORTILLA, M. (1992): “Mecanismos de producción y reproducción social de las elites económicas y del capitalismo en la Restauración”, Historia Contemporánea, 8, pp. 143-176.

LANZINGER, M. (2017): “El matrimonio ente consanguíneos y afines. Política y procedimientos para la obtención de las dispensas en el siglo XIX”, en HENAREJOS LÓPEZ, J.F. y IRIGOYEN LÓPEZ (eds.), A.: Escenarios de familia: trayectorias, estrategias y pautas culturales, siglos XVI-XIX, Murcia, Universidad, pp.423-431.

LARRAZA MICHELTORENA, M.M. (2002): "Elites políticas en la Restauración española: una mirada desde la prosopografía”, Memoria y Civilización, 5, pp. 275305.

LÓPEZ-MORELL, M.A. (2003): "Peñarroya: un modelo expansivo de corporación minero-industrial, 1881-1936”, Revista de Historia Industrial, 23, pp. 95-135.

LÓPEZ-MORELL, M.A. (2011): “El factor empresarial en el desarrollo históricoeconómico de la Región de Murcia", X Congreso Internacional de la $A E H E$, Sevilla, Universidad Pablo de Olavide, pp. 1-32.

LÓPEZ-MORELL, M.A. (2016): The House of Rothschild in Spain, 1812-1941, New York, Routledge.

LÓPEZ-MORELL, M.A. y PÉREZ DE PERCEVAL VERDE, M.A. (2016): “Empresas y empresarios en la minería murciana contemporánea”, Murgetana, 134, pp. 51-77. 
LORENZO SOLANO, J.A. (1989): Biografía de José Maestre Pérez (1866-1933). El gran mito político de Cartagena, Murcia, Librería Tajo.

LUENGO, J. (2016): “Las élites liberales: una sociedad conyugal”, Historia Social, 86, pp. 91-108.

MARTÍNEZ LEAL, J. (1993): República y Guerra Civil en Cartagena (1931-1939), Ayuntamiento de Cartagena - Universidad de Murcia, Murcia.

MARTÍNEZ TORNEL, J.: (1887): Guía de Murcia, Murcia, Imp. del Diario de Murcia.

MCDONOGH, G.W. (1989): Las buenas familias de Barcelona. (Historia social de poder en la era industrial), Barcelona, Omega.

MORENO LUZÓN, J. (1996): "El poder público hecho cisco. Clientelismo e instituciones políticas en la España de la Restauración”, en ROBLES EGEA, A. (comp.): Política en penumbra. Patronazgo y clientelismo políticos en la España contemporánea, Madrid, Siglo XXI, 1996, pp. 169-190.

MORENO LUZÓN, J. (1998): Romanones. Caciquismo y política liberal, Madrid, Alianza.

MUÑOZ LÓPEZ, P. (2001): Sangre, amor e interés. La familia en la España de la Restauración, Madrid, Marcial Pons - UAM Ediciones.

PEÑA GUERRERO, M.A. (1997): “La familia política: la utilización política del parentesco durante la Restauración”, en CASEY, J. y HERNÁNDEZ FRANCO, J. (eds.), Familia, parentesco y linaje, Murcia, Universidad de Murcia, pp. 415-432.

PÉREZ ROJAS, J. (1986): Cartagena 1874-1936. (Transformación urbana y arquitectura), Murcia, Editora Regional de Murcia.

PÉREZ Y GÓMEZ, A. (1965): Don Juan de la Cierva, ministro de Alfonso XIII (18641938), Murcia, Academia Alfonso X el Sabio.

PIQUERAS ARENAS, J.A. (1998): “Negocios y política en el siglo XIX español”, en PANIAGUA, J. y PIQUERAS, J.A. (eds.): Poder económico y poder político, Valencia, Fundación Instituto Historia Social.

PREGO DE LIS, A. (2005): "El arquetipo del capitalismo minero en La Unión. Miguel Zapata Sáez El Tío Lobo”, Cartagena Histórica, pp. 12-24.

PREGO DE LIS, A.: "La familia Zapata Maestre y el paisaje de la Comarca de Cartagena",https.//es.scrib.com/document/235090918/La-Familia-Zapata-Maestre. Consultado el 15 de octubre de 2019.

PRO RUIZ, J. (1995): "Las élites de la España liberal: clases y redes en la definición del espacio social (1808-1931)”, Historia Social, 21, pp. 47-69. 
REHER, D.S. (1996): La familia en España. Pasado y presente, Madrid, Alianza Editorial.

REY REGUILLO, F. y MORENO LUZÓN, J. (1996): “Semblanza de la elite parlamentaria en la Crisis de la Restauración (1914-1923)", Revista de Estudios Políticos, 93, pp. 177-201.

ROMÁN CERVANTES, C. (1993): "La propiedad de la tierra en la comarca del Campo de Cartagena (SS. XIX-XX)”, Áreas. Revista Internacional de Ciencias Sociales, 15, pp. 137-154

ROMÁN CERVANTES, C.: (1996): Uso y explotación de la tierra en la comarca del Campo de Cartagena, (siglos $X I X$ y $X X$ ), Madrid, Ministerio de Agricultura, Pesca y Alimentación.

RUIZ ABELLÁN, E. (1991): Modernización política y elecciones generales en Murcia durante el reinado de Alfonso XIII (1903-1923), Murcia, Academia Alfonso X el Sabio.

SAMPEDRO ESCOLAR, J.L. (2021): “José Maestre Pérez". Consulta 20 de febrero de 2021 (http://dbe.rah.es/biografias/16086/jose-maestre-perez).

SIERRA, M. (2000): “La Casa Ybarra: Política de honor y política de interés”, Historia Social, 36, pp. 3-20.

SIERRA ALONSO, M. (1990): "Empresarios y políticos en la Sevilla de la Restauración: la familia Ybarra”, Espacio, Tiempo y Forma, Serie V, Historia Contemporánea, 3, pp. 143-158.

SOLDEVILLA, F. (1920): El año político 1919. Madrid, Imp. de Julio Cosano.

TUÑÓN DE LARA, M. (1967): Historia y realidad del poder, Madrid, Cuadernos para el Diálogo.

TUSELL, J. (1976): Oligarquía y caciquismo en Andalucía (1890-1923), Barcelona, Planeta.

VILAR, J.B.; EGEA BRUNO, P.M. y VICTORIA MORENO, D. (1987): El movimiento obrero en el distrito minero de Cartagena-La Unión (1840-1930), 2ª ed. Murcia, Academia Alfonso X el Sabio.

WANDOSELL FERNÁNDEZ DE BOBADILlA, G. (2012): Pío Wandosell Gil. Memorias de un empresario audaz. Retrato de una época: La Unión 1868-1920, La Unión, Ayuntamiento de La Unión. 
Pedro Ma Egea Bruno es catedrático de Historia contemporánea en la Universidad de Murcia. Académico correspondiente por Cartagena (Murcia) de la Real Academia de la Historia. Entre sus obras destacan: El distrito minero de Cartagena en torno a la primera Guerra Mundial (1909-1923); La represión franquista en Cartagena (1939-1945); La política y los políticos en la Cartagena de Alfonso XIII (1902-1923); Cartagena. Imagen y memoria, una historia gráfica e cuatro tomos, y La enseñanza primaria en Cartagena durante la II República y a Guerra Civil (1931-1939). Es coautor -con Juan B. Vilar y diego Victoria- de La minería murciana contemporánea I (1840-1930) y II (1930-1985) y de El movimiento obrero en el distrito minero de Cartagena, La Unión (1840-1930). A él corresponde el estudio de la Edad Contemporánea en la obra colectiva Manual de Historia de Cartagena. En la actualidad su obra se centra en la II República, Guerra Civil y etapa franquista, avanzando en estudios sobre la economía, la política, la ideología, la cultura, la vida cotidiana, las emigraciones y la mujer. pmegea@um.es 